\title{
PENGARUH METODE ACCELERATED LEARNING DENGAN PENDEKATAN SAVI TERHADAP HASIL BELAJAR SISWA PADA MATERI POKOK TEKANAN DI KELAS VIII SEMESTER II SMP NEGERI 1 SELESAI T.A. $2013 / 2014$
}

\author{
Ricca Mauliza Br Lubis dan Eva Marlina Ginting \\ ricamauliza@gmail.com \\ Jurusan Fisika FMIPA Universitas Negeri Medan \\ Jalan Willem Iskandar Pasar V Medan, 20221
}

\begin{abstract}
This study aims to determine the effect of teaching method possible Accelerated Learning with SAVI approach to learning outcomes the second semester of eighth grade students in the subject matter pressure in SMP Negeri 1 Completed TA 2013/2014. This research is quasiexperimental. The population is the entire second semester of eighth grade students of SMP Negeri 1 Done. Sampling was done by cluster random sampling by taking 2 classes from 9 randomized class VIII- 1 as an experimental class and class VIII- 3 as a control class. The instrument used to determine student learning outcomes are achievement test in the form of multiple choice questions with number 20. Learning method possible application of research results Accelerated Learning with SAVI approach showed that: (1) There is an increase in student learning activities begin until the first meeting of the third, of the average value of the student activity can be determined student learning activities included in the active category; (2) Based on the test results obtained studying the average value of 81.09 posttest experimental class and control class is 62.81. Calculation of data is done by using t-test of the party with $a=0.05$, obtained that $t$ count $>t$ table so it can be concluded that no effect of learning methods Accelerated Learning with SAVI approach to learning outcomes of students in the subject matter of pressure in the second semester of eighth grade SMP Negeri 1 Completed
\end{abstract} TA 2013/2014.

Keywords : Accelerated Learning Methods SAVI Approach, QuasiExperimental, Learning Outcomes

\section{PENDAHULUAN}

Pendidikan adalah salah satu bentuk perwujudan kebudayaan manusia yang dinamis dan sarat perkembangan. Perubahan dalam arti perbaikan pendidikan pada semua tingkat perlu terus-menerus dilakukan sebagai antisipasi kepentingan masa depan.

Memasuki abad ke-21, sistem pendidikan nasional menghadapi tantangan yang sangat kompleks dalam menyiapkan kualitas sumber daya manusia (SDM) yang mampu 
bersaing di era global. Upaya yang tepat untuk menyiapkan sumber daya manusia (SDM) yang berkualitas dan satu-satunya wadah yang dapat dipandang dan seyogianya berfungsi sebagai alat alat untuk membangun SDM yang bermutu tinggi adalah pendidikan.

Pemerintah telah menyelenggarakan perbaikan-perbaikan peningkatan mutu pendidikan pada berbagai jenis dan jenjang untuk mencapai tujuan pendidikan nasional. Kegiatan proses pembelajaran di sekolah merupakan usaha dalam meningkatkan kualitas pendidikan nasional, karena sekolah merupakan salah satu perangkat pendidikan. Mengingat fisika merupakan salah satu mata pelajaran yang penting diberbagai jenjang pendidikan, maka sudah sewajarnya mata pelajaran fisika dikembangkan dan diperhatikan oleh semua pelaku pendidikan.

Permasalahan utama dalam pembelajaran adalah bagaimana cara penyampaian materi kepada siswa agar siswa dapat tertarik untuk belajar. Menurut Trianto (2009:17), cara mengajar yang baik merupakan kunci dan prasarat bagi siswa untuk dapat belajar dengan baik. Kegiatan belajar mengajar yang selama ini dilakukan hanya berpusat pada guru dan cenderung hanya menghapal rumus-rumus dan mengerjakan soal. Padahal pelajaran fisika merupakan pelajaran yang aplikasinya banyak kita temui di daerah sekitar kita, Pelajaran fisika lebih menekankan pada pemberian langsung untuk meningkatkan kompetensi agar siswa mampu berpikir kritis dan sistematis dalam memahami konsep fisika, sehingga siswa memperoleh pemahaman yang benar tentang fisika. Pemahaman yang benar akan pelajaran fisika akan sangat berpengaruh terhadap hasil belajar siswa. Menurut Bloom (dalam suprijono, 2009:5), hasil belajar mencakup kemampuan kognitif, afektif, dan psikomotorik.

Berdasarkan hasil studi pendahuluan yang dilakukan di SMP Negeri 1 Selesai kelas VIII dengan menyebarkan angket kepada siswa diperoleh data bahwa dari 32 siswa, 17 orang mengatakan bahwa fisika itu sulit dan kurang digemari, sedangkan untuk nilai ulangan yang diperoleh siswa, 24 orang mengaku memperoleh nilai rata-rata 50-60, dan lebih dari setengah siswa mengatakan mengalami kesulitan dalam mengerjakan tugas fisika dari guru. Selain dengan angket peneliti juga melakukan wawancara dengan guru bidang studi fisika yaitu bapak Elias Sinaga,S.Pd yang mengatakan bahwa motivasi dan minat siswa sangat kurang dalam pelajaran fisika sehingga hasil belajar fisika kurang maksimal yang berdampak tidak tercapainya ketuntasan belajar pada mata pelajaran fisika. Hal ini dapat dilihat dari rata-rata nilai hasil ujian semester untuk mata pelajaran fisika di kelas pada tahun 2011/2012 rata-rata nilainya yaitu 63 dan pada tahun 2012/2013 rata-rata nilai hanya 65 . Nilai itu tentu saja masih tergolong rendah mengingat KKM (Kriteria Ketuntasan Minimal) sekolah tersebut adalah 70. Adapun pada tahun 2013/2014 KKM di sekolah naik menjadi 75. Dari hasil observasi juga terungkap bahwa metode pembelajaran yang digunakan kurang bervariasi pembelajaran yang digunakan adalah pembelajaran konvensional yaitu dengan menggunakan metode ceramah satu arah, jarang sekali diskusi, demonstrasi maupun kegiatan praktikum, siswa hanya mendengarkan penjelasan guru 
tanpa ikut aktif terlibat dalam pembelajaran sehingga mengakibatkan motivasi serta minat siswa kurang dalam pelajaran fisika.

Diperlukan salah satu upaya untuk mengatasi permasalahan dalam hal ini, yaitu dengan menggunakan pendekatan dan motode pembelajaran yang lebih efektif, yang dapat meningkatkan minat, semangat, kemampuan untuk dapat bekerja bersama teman dalam menemukan suatu permasalahan, dan kegembiraan siswa serta dengan sendirinya diharapkan dapat meningkatkan hasil belajar siswa.

Adapun pendekatan serta metode pembelajaran yang perlu dikembangkan yang diharapkan dapat meningkatkan hasil belajar siswa melalui penerapan bekerja sama memecahkan masalah, menemukan sesuatu untuk dirinya dan saling mendiskusikan masalah tersebut dengan teman-temannya yaitu dengan menerapkan metode Accelerated Learning dangan pendekatan SAVI.

Menurut Nicholl dan Rose (2002:37) Accelerated Learning berusaha memadukan aneka permainan dan aktivitas, emosi dan musik, relaksasi, visualisasi, permainan peran, warna, peta konsep, cara berpikir positif dan suasana emosional yang menyenangkan sehingga proses belajar menjadi kejadian yang menyenangkan dan bebas-tekanan. Meier (2000:37), juga menganggap Accelerated Learning adalah hasil yang dicapai, bukan suatu metode atau pendekatan yang digunakan.

Beberapa hasil penelitian membuktikan bahwa penggunaan pembelajaran Accelerated Learning dangan pendekatan SAVI dapat meningkatkan prestasi belajar siswa, meningkatkan penguasaan konsep, meningkatakan kualitas pembelajaran, dapat meningkatkan kemapuan hubungan sosial, peningkatan hasil belajar siswa, dan meningkatakan Motivasi belajar siswa.

Berdasarkan uraian di atas, maka penulis tertarik untuk melakukan penelitian dengan judul : "Pengaruh Metode Accelerated Learning dengan Pendekatan SAVI Terhadap Hasil Belajar Siswa pada Materi Pokok Tekanan di Kelas VIII Semester II SMP Negeri 1 Selesai T.A. 2013/2014".

\section{METODE PENELITIAN}

Penelitian ini termasuk jenis penelitian quasi experiment yaitu merupakan penelitian yang dimaksudkan untuk mengetahui ada tidaknya akibat dari sesuatu yang dikenakan pada subjek yaitu siswa.

Penelitian ini akan dilaksanakan di SMPN 1 Selesai yang beralamat di Jalan Ki Hajar Dewantara Sei Limbat, Kecamatan Selesai, kelas VIII semester II T.A 2013/2014.

Populasi penelitian ini adalah seluruh siswa kelas VIII semester genap SMA Negeri 1 Selesai T.A 2013/2014 yang terdiri dari kelas 9 kelas yaitu dari kelas VIII-1 sampai VIII-9. Sampel penelitian ditentukan dengan teknik clusterrandom sampling dan diperoleh dua kelas yaitu kelas VIII-1 dan kelas VIII-3 yang masingmasing merupakan kelas eksperimen (pembelajaran menggunakan metode Accelerated Learning dangan pendekatan SAVI) dan kelas kontrol (pembelajaran menggunakan pembelajaran konvensional).

Instrumen yang digunakan adalah tes hasil belajar siswa dan observasi aktivitas siswa. Tes hasil belajar siswa berjumlah dua puluh (20) soal dalam bentuk pilihan 
berganda dengan empat pilihan (option) yaitu a, b, c, dan d. tes ini diberikan sebanyak 2 kali yaitu pada saat pretes dan postes. Sedangkan observasi yang dimaksud dalam penelitian ini adalah observasi terhadap subjek penelitian yang dilakukan untuk mengetahui aktivitas siswa ketika belajar. Observasi yang dilakukan bersifat langsung dan dilakukan oleh dua orang pengamat (observer). Manfaat dilakukan observasi yaitu memperoleh informasi balikan (feed back) guru di dalam kegiatan belajar mengajar. Penelitian ini melibatkan dua kelas yang diberi perlakuan yang berbeda. Menurut Suprijono (2009:4), prinsipprinsip belajar adalah perubahan perilaku sebagai hasil belajar. Untuk mengetahui hasil belajar fisika siswa dilakukan dengan memberikan tes pada kedua kelas sebelum dan sesudah diberikan perlakuan. Rancangan penelitian ini sebagai berikut:

Tabel 1. Two Group Pretes - Posttest

\begin{tabular}{|l|c|c|c|}
\multicolumn{1}{|c|}{ Design } \\
\hline Kelas & $\begin{array}{c}\text { Pre } \\
\text { tes }\end{array}$ & $\begin{array}{c}\text { Perlakua } \\
\mathrm{n}\end{array}$ & $\begin{array}{c}\text { Poste } \\
\mathrm{s}\end{array}$ \\
\hline Eksperimen & $\mathrm{T}_{1}$ & $\mathrm{X}_{1}$ & $\mathrm{~T}_{2}$ \\
\hline Kontrol & $\mathrm{T}_{1}$ & $\mathrm{X}_{2}$ & $\mathrm{~T}_{2}$ \\
\hline
\end{tabular}

Keterangan :

$\mathrm{T}_{1}=$ Pretes yang diberikan kepada kelas eksperimen dan kelas Kontrol sebelum diberikan perlakuan. Tes yang diberikan berupa tes hasil belajar pada materi pokok tekanan.

$\mathrm{T}_{2}=$ Postes diberikan kepada kelas eksperimen dan kelas Kontrol.

$\mathrm{X}_{1}=$ Perlakuan 1 yang diberikan Pembelajaran dengan menggunakan metode Accelerated Learning dengan pendekatan SAVI.
$\mathrm{X}_{2}=$ Perlakuan 2 yang diberikan dengan pembelajaran konvensional.

Dari hasil pretest yang dipeoleh dilakukan uji Normalitas, uji Homogenitas dan uji kesamaan ratarata (uji-t) untuk menentukan apakah data berdistribusi normal, homogen dan tidak ada perbedaan yang signifikan antara hasil belajar kedua kelas. Selanjutnya kedua kelas diberi perlakuan yang berbeda, kelas eksperimen diberi perlakuan dengan menggunakan metode Accelerated Learning dengan pendekatan SAVI dan kelas kontrol diberi perlakuan dengan menggunakan pembelajaran konvensional. Setelah itu kedua kelas diberi postes. Dari hasil postes yang diperoleh dilakukan kembali uji Normalitas, Homogenotas dan uji kesamaan rata-rata (uji-t) untuk menentukan apakah data hasil belajar siswa digolongkan normal, homogen dan ada perbedaan yang signifikan antara hasil belajar kedua kelas yang menginduksi bahwa ada pengaruh atau tidak terhadap hasil belajar siswa.

\section{HASIL DAN PEMBAHASAN}

Data dari hasil penelitian ini berupa hasil belajar siswa yaitu pretest dan posttest dan hasil observasi.

Tabel 2. Data Pretes Kelas

Eksperimen dan Kelas Kontrol

\begin{tabular}{|c|c|c|c|c|c|c|c|}
\hline \multicolumn{4}{|c|}{ Kelas Eksperimen } & \multicolumn{4}{|c|}{ Kelas Kontrol } \\
\hline $\mathrm{N}_{0}$ & Nilai & Frekuensi & Rata-rata & $\mathrm{N}_{0}$ & Nilai & Frekuensi & Rata-rata \\
\hline 1 & 15 & 4 & \multirow{8}{*}{30,31} & 1 & 15 & 5 & \multirow{8}{*}{29,84} \\
\hline 2 & 20 & 5 & & 2 & 20 & 5 & \\
\hline 3 & 25 & 5 & & 3 & 25 & 5 & \\
\hline 4 & 30 & 5 & & \begin{tabular}{|l|}
4 \\
\end{tabular} & 30 & 4 & \\
\hline 5 & 35 & 4 & & 5 & 35 & 4 & \\
\hline 6 & 40 & 4 & & 6 & 40 & 4 & \\
\hline 7 & 45 & 3 & & \begin{tabular}{|l|}
7 \\
\end{tabular} & 45 & 3 & \\
\hline 8 & 50 & 2 & & 8 & 50 & 2 & \\
\hline
\end{tabular}


Selain data pretes pada penelitian ini juga diperoleh data postes dengan rincian sebagai berikut:

Tabel 3. Data Postes Kelas Eksperimen dan Kelas Kontrol

\begin{tabular}{|c|c|c|c|c|c|c|c|}
\hline \multicolumn{4}{|c|}{ Kelas Eksperimen } & \multicolumn{4}{|c|}{ Kelas Kontrol } \\
\hline No & Vilai & Frekuensi & Rata-pata & . 10 & Nilai & Frekuensi & Rata-rata \\
\hline 1 & 65 & 2 & \multirow{8}{*}{81,09} & 1 & 45 & 1 & \multirow{8}{*}{62,81} \\
\hline 2 & 70 & 4 & & 2 & 50 & 4 & \\
\hline 3 & 75 & 5 & & 3 & 55 & 5 & \\
\hline 4 & 80 & 6 & & 4 & 60 & 6 & \\
\hline 5 & 85 & 6 & & 5 & 65 & 5 & \\
\hline 6 & 90 & 5 & & 6 & 70 & 5 & \\
\hline \multirow[t]{2}{*}{7} & 95 & 4 & & 7 & 75 & 4 & \\
\hline & & & & 8 & 80 & 2 & \\
\hline
\end{tabular}

Penelitian diawali dengan memberikan pretes terhadap kedua sampel dengan jumlah soal 20 butir dalam bentuk pilihan berganda dengan 4 opsi yaitu pada kelas eksperimen dan kelas kontrol. Hasil pretes kelas eksperimen memperoleh nilai rata-rata 30,31 dan nilai ratarata kelas kontrol adalah 29,84. Dengan menggunakan uji $t$ dua pihak ternyata hasil tersebut menyatakan bahwa tidak ada perbedaan yang signifikan antara kemampuan awal siswa pada kelas eksperimen terhadap kemampuan awal siswa pada kelas kontrol sebelum diberi perlakuan.

Kemudian pada kedua kelas diberi perlakuan yang berbeda yaitu pada kelas eksperimen diberi perlakuan menggunakan metode Accelerated Learning dengan pendekatan SAVI sedangkan kelas kontrol diberi perlakuan dengan menggunakan pembelajaran konvensional. Setelah diberikan perlakuan kedua kelas diberikan tes akhir (postes) untuk melihat adanya pengaruh yang signifikan terhadap hasil belajar siswa. Hal ini dapat dilihat dari hasil rata-rata postes kelas eksperimen yaitu 81,09, sedangkan nilai rata-rata postes kelas kontrol 62,81. Hasil uji normalitas untuk kedua sampel menunjukkan bahwa kedua kelas berdistribusi normal dimana $\mathrm{L}_{\text {hitung }}$ tidak melebihi Llabel dan berasal dari populasi yang homogen. Hasil uji hipotesis untuk postes menggunakan uji t satu pihak pada taraf signifikan $\alpha=0,05$ diperoleh $t_{\text {hitung }}>t_{\text {tabel }}=$ $7,85>1,669$ yang berarti bahwa ada pengaruh metode pembelajaran Accelerated Learning dengan pendekatan SAVI terhadap hasil belajar siswa pada materi pokok tekanan di kelas VIII semester II SMP Negeri 1 Selesai T.A. 2013/2014.

Observasi dilakukan pada kegiatan diskusi untuk tiap pertemuan yang terdiri dari tiga kali pertemuan. Observasi dilakukan hanya pada kelas eksperimen. Hasil perkembangan aktivitas belajar siswa dapat dilihat pada grafik berikut :

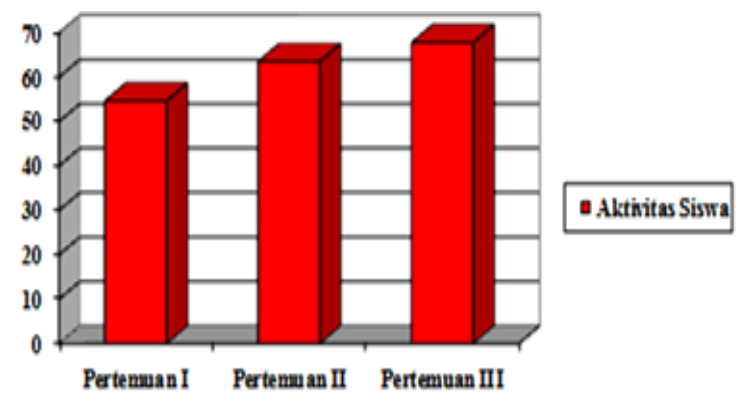

Gambar 1: Rata-Rata Presentase Aktivitas Siswa Kelas Eksperimen

Dari tabel diatas dapat dilihat bahwa perkembangan aktivitas siswa di kelas eksperimen mengalami peningkatan selama menerima metode pembelajaran Accelerated Learning dengan pendekatan SAVI. Penelitian dengan penerapan pembelajaran Accelerated Learning ini sudah pernah diteliti 
oleh peneliti-peneliti, antara lain yaitu:

Hasil penelitian Hermansyah Amir (Hermansyah Amir, 2008) dengan judul "Penerapan Pendekatan Permbelajaran Somoatis Audiotori Visual Dan Intelektual (SAVI) Berbantuan Media Computer Untuk Meningkatakan Kualitas Pembelajaran Kimia Fisika II" menyatakan bahwa hasil yang di capai siswa memuaskan sampai empat siklus dari pembelajaran dan diperoleh peningkatan hasil belajar yaitu sebesar $84,54 \%$.

Hasil penelitian Ahmad Fauzul dan Sri Astutik (Ahmad Fauzul dan Sri Astutik ,2012) dengan judul "Penerapan Pendekatan Accelerated Learning dengan Whole Brain Teaching Dalam Pembelajaran Fisika Di SMP" Terdapat peningkatan hasil belajar siswa di kelas eksperimen sebesar 78,03 dan terdapat peningkatan aktivitas siswa sebesar 74,665 \%.

Hasil penelitian Nares, Parasti,(Nares Parasti, 2011) dengan judul "Medel Accelerated Learning Meningkatakan Penguasaan Konsep IPA materi Alat Indra" menyatakan bahwa berdasarkan hasil tes akhir menunjukkan bahwa Metode Accelerated Learning dapat meningkatakan penguasaan konsep alat indra siswa kelas IV SDN Jati Lawang.

\section{KESIMPULAN DAN SARAN Kesimpulan}

Berdasarkan hasil penelitian yang diperoleh dari hasil analisa data dan pengujian hipotesis maka dapat disimpulkan sebagai berikut : (1) Rata-rata hasil belajar siswa pada kelas eksperimen yang diberi perlakuan dengan motode pembelajaran Accelerated Learning dengan pendekatan SAVI adalah 81,09 (Melebihi dari nilai KKM termasuk kategori sangat baik). (2) Rata-rata hasil belajar siswa pada kelas kontrol yang diberi perlakuan dengan pembelajaran konvensional adalah 62,81(Kurang dari nilai KKM termasuk dalam kategori cukup baik). (3) Aktivitas siswa yang diajar dengan menggunakan motode pembelajaran Accelerated Learning dengan pendekatan SAVI mengalami peningkatan, yaitu pada pertemuan I sebesar 54.65 dengan katagori cukup aktif, pertemuan II sebesar 63.54 dengan katagori aktif, dan pertemuan III sebesar 69.79 dengan katagori aktif. Dengan nilai rata-rata aktivitas siswa dari tiga pertemuan adalah sebesar 62.86 dengan kategori aktif. (4) Ada pengaruh Metode Accelerated Learning dengan pendekatan SAVI terhadap hasil belajar siswa pada materi pokok Tekanan di Kelas VIII semester II SMP Negeri 1 Selesai T.A. 2013/2014.

\section{Saran}

Berdasarkan hasil dan kesimpulan dalam penelitian ini, maka peneliti mempunyai beberapa saran,yaitu : (1) Bagi peneliti selanjutnya yang ingin melakukan penelitian dengan menggunakan metode pembelajaran Accelerated Learning dengan pendekatan SAVI disarankan lebih memperhatikan dan membimbing siswa selama bekerja dalam kelompok dengan cara aktif bertanya kepada tiap siswa tentang apa yang telah dikerjakannya dalam kelompok dengan begitu siswa akan lebih termotivasi untuk aktif dalam menyelesaikan tugas kelompok. (2) Bagi peneliti selanjutnya disarankan sebelum memulai proses pembelajaran terlebih dahulu 
dijelaskan kepada siswa bagaimana pelaksanaan metode pembelajaran Accelerated Learning dengan pendekatan SAVI, sehingga pada saat pelaksanaan pembelajaran para siswa sudah mengerti apa yang akan dilakukan dan tidak menyita waktu untuk pembelajaran yang lain.

\section{DAFTAR PUSTAKA}

Arikunto, S., (2006), Dasar-Dasar Evaluasi Pendidikan, Bumi Aksara, Jakarta.

Amir Hermansyah dan Menda Sura ,(2012), Jurnal Exacta, Penerapan Pendekatan Permbelajaran Somoatis Audiotori Visual Dan Intelektual (SAVI) Berbantuan Media Computer Untuk Meningkatakan Kualitas Pembelajaran Kimia Fisika II, $10: 1-8$.

Fauzul Albab dan Sri Astutik (2012) Penerapan Pendekatan Accelerated Learning dengan Whole Brain Teaching Dalam Pembelajaran Fisika Di SMP, 1 $: 1-7$

Meier, D., (2000), The Accelerated Learning Handbook, Kaifa, Bandung.

Nicholl, J, M., dan Rose, C., (2002), Accelerated Learning For The 21ST Century Cara Belajar Cepat Abad XXI, Nuansa, Bandung.

Parasti, Nares, (2011), Jurnal Pendidikan MIPA, Model Accelerated Learning Meningkatakan Penguasaan Konsep IPA materi Alat Indra, 3 : $1-7$.

Rose, C., (2007), Super Accelerated Learning, Jabal, Bandung.
Trianto, (2009), Mendesain Model Pembelajaran InovatifProgresif:Konsep, Landasan dan implementasinya pada Kurikulum Tingkat Satuan Pendidikan, Penerbit Kencana, Jakarta.

Sardiman, (1986), Interaksi dan Motivasi Belajar Mengajar, PT Raja Grafindo Persada, Jakarta. Suprijono, A., (2009), Cooperatif Learning Teori \& Aplikasi PAIKEM, Pustaka Belajar, Yogyakarta. 